\title{
Intervenciones terapéuticas en pitiriasis rosada: revisión de la literatura
}

Therapeutic interventions in pityriasis rosada: a review of the literature

\author{
Susana Mejía-Mesa', Sofía Medina-Escobar¹, Jorge Hernando Donado-Gómez ${ }^{2}$ \\ 1. Estudiante, XI semestre, Facultad de Medicina, Universidad Pontificia Bolivariana, Medellín, Colombia \\ 2. Médico, epidemiólogo clínico; profesor titular, Universidad Pontificia Bolivariana; Hospital Pablo Tobón Uribe, Medellín, \\ Colombia
}

\section{RESUMEN}

Introducción: La pitiriasis rosada es una erupción exantemática aguda y su etiología está asociada con la reactivación de los virus herpes 6 y 7. El tratamiento es controversial, se han sugerido diversas intervenciones buscando impactar en la historia natural de la enfermedad.

Objetivo: Hacer una revisión de la literatura sobre los tratamientos disponibles.

Métodos: Revisión de las publicaciones que aparecen en Cochrane, Pubmed, Medline, Lilacs y Embase, incluyendo estudios aleatorizados y controlados, en los cuales se evaluaron intervenciones terapéuticas.

Resultados: Se incluyeron 13 estudios (667 pacientes) que comparaban el uso de terapia antiviral, antibióticos, esteroides sistémicos y radiación ultravioleta.

Conclusiones: Se encontró información que permite recomendar el uso del aciclovir para disminuir el tiempo de erupción. No se recomienda el uso de azitromicina. El tratamiento con esteroides se debe reservar para casos más graves y la fototerapia, a pesar de tener información desactualizada, muestra datos favorecedores.

PALABRAS CLAVE: pitiriasis rosada, intervenciones, revisión bibliográfica

\section{SUMMARY}

Introduction: Pityriasis rosea is an acute exanthematic eruption; its etiology is associated with the reactivation of herpes virus 6 and 7. The treatment is controversial; several interventions have been suggested seeking to impact on the natural history of the disease.

Objective: To accomplish a systematic review of the literature on available therapies.

Methods: Bibliographic review of publications in Cochrane, Pubmed, Medline, Lilacs and Embase, including randomized controlled studies where therapeutic interventions were evaluated.

Results: Thirteen studies (667 patients) were included, comparing the use of antiviral therapy, antibiotics, systemic steroids and ultraviolet radiation.

Conclusions: We found evidence that allows us to recommend the use of aciclovir to reduce the time of eruption. The use of azithromycin is not recommended.
Correspondencia:

Susana Mejía-Mesa

Email:

susana.mejiao403@hotmail. com

Recibido: 13/07/2018

Aceptado: 12/10/2018

Conflictos de interés:

No se reportan conflictos de interés.

Financiación:

Ninguna. 
Steroid therapy should be reserved for more severe cases and the use of phototherapy despite having outdated evidence shows favorable data.

KEY WORDS: Pityriasis rosea, interventions, bibliographic review

\section{INTRODUCCIÓN}

La pitiriasis rosada es una erupción exantemática aguda que, a menudo, se resuelve de manera espontánea en 2 a 12 semanas, pero puede durar hasta 5 meses $^{(1)}$. Suele presentarse entre los 10 y los 43 años, en las estaciones de otoño y primavera. Se relaciona con la reactivación del virus herpes (Human Herpes Virus, HHV) 6 o HHV-7. Inicialmente, se manifiesta con un parche ovalado en el tronco, de 2 a $5 \mathrm{~cm}$, con escamas en collar de color salmón en la periferia, también llamado parche heráldico ${ }^{(2,3)}$, seguido una a dos semanas después, por una erupción generalizada caracterizada por pápulas y parches que siguen las líneas de tensión de la piel, en un patrón de árbol de navidad, que suelen estar confinadas al tronco y las superficies proximales de las extremidades. Estas lesiones, generalmente, no son dolorosas pero los pacientes presentan prurito moderado a grave ${ }^{(1)}$. Muy rara vez, los pacientes presentan síntomas sistémicos asociados con la lesión dermatológica ${ }^{(4)}$. Debido a esto y a la característica de ser de resolución espontánea, el tratamiento ha sido controversial $^{(2)}$.

La hipótesis de tener una etiología viral ha sido secundada al presentarse con pródromos, en grupos de personas y en épocas específicas, aunque no se ha determinado con exactitud la verdadera causa de la reacción exantemática ${ }^{(5)}$.

El diagnóstico de la pitiriasis rosada es clínico, ante la presencia de las lesiones con su distribución característica. El parche heráldico orienta el diagnóstico del médico tratante, aunque en ocasiones puede confundirse con la tinea corporis y para diferenciarlos se puede hacer el test de KOH. Además, se puede tomar una biopsia para hacer el diagnóstico, pero, generalmente, no es necesario ${ }^{(1,5)}$.

La mayoría de los pacientes no requieren tratamiento. Cuando los síntomas son más graves, el tratamiento recomendado para la pitiriasis rosada se basa en tres pilares: medicamentos tópicos, medicamentos sistémicos y fototerapia. El tratamiento sistémico incluye antivirales, como el aciclovir, antibióticos, como la eritromicina, y glucocorticoides sistémicos. Para el tratamiento tópico, se usan los emolientes, los esteroides en crema y los antihistamínicos tópicos, y, por último, la fototerapia puede ser con luz solar o con rayos ultravioleta (UV) ${ }^{(2)}$.

En la actualidad, el uso de algunos tratamientos para la pitiriasis rosada sigue siendo controversial, ya que en su mayoría se basan en la experiencia profesional y no en resultados de ensayos clínicos, debido a que se han reportado algunas contradicciones en diferentes estudios y no se ha llegado a un consenso sobre cuál tratamiento es más efectivo o cuál verdaderamente resuelve la enfermedad.

Otra de las limitaciones que tiene la elección del tratamiento más adecuado, son las múltiples teorías que hay sobre la etiología de esta enfermedad. Es por esto que se han planteado varios tratamientos, desde antivirales hasta la radiación ultravioleta B (UVB).

El objetivo del presente estudio fue realizar una revisión de la literatura sobre los tratamientos para esta entidad.

\section{MATERIALES Y MÉTODOS}

\section{Protocolo}

La revisión de la literatura se hizo con base en los criterios para la elaboración de protocolos en revisiones sistemáticas de la Colaboración Cochrane ${ }^{(6)}$ y el Prisma $P^{(7)}$.

\section{Criterios de elegibilidad}

Se incluyeron ensayos clínicos que se pudieran descargar en texto completo en los que se evaluaron las intervenciones tópicas, como emolientes, antihistamínicos tópicos, corticosteroides en crema, fototerapia con luz solar o rayos UV, y los tratamientos sistémicos con antihistamínicos, corticosteroides, antibióticos y antivirales orales.

Los resultados evaluados fueron la mejoría clínica de las lesiones en la piel y la mejoría del prurito, y la presencia de efectos secundarios a las intervenciones. No se hizo restricción por tiempo, idioma ni estado de la publicación.

\section{Fuentes de información y estrategias de búsqueda}

Se hizo una búsqueda independiente por parte de dos investigadores en las bases de datos de Embase, Lilacs, Central y Pubmed. Se hizo una búsqueda en el registro de la Colaboración Cochrane (Central) de todos los ensayos clínicos registrados, usando las palabras: pityriasis rosea; para Pubmed, se emplearon los términos 
"pityriasis rosea" y "randomized controlled trial”; para Embase, "pityriasis rosea”, "treatment” y "controlled clinical trial”; para Lilacs, "pityriasis rosea” y "controlled trial”.

\section{Selección de artículos}

De manera independiente, dos autores se encargaron de la revisión de los artículos obtenidos y de los criterios de elegibilidad. Cualquier desacuerdo entre ellos fue resuelto por un tercer autor. La concordancia entre los evaluadores se evaluó por medio del coeficiente kappa de Cohen.

\section{Extracción de los datos}

Para cada artículo, se implementó un formulario de extracción de datos de la siguiente información: tipo de estudio, edad promedio de los pacientes, sexo, intervención, comparación y resultado.

\section{Riesgo de sesgos}

Para valorar los sesgos, se empleó el formato propuesto por la Colaboración Cochrane para la valora- ción del riesgo de sesgos de los estudios primarios ${ }^{(6)}$. De manera individual, dos investigadoras evaluaron la forma de aleatorización, el ocultamiento de la secuencia aleatoria, cómo y quiénes fueron cegados a la intervención, cómo fue la recolección de los datos, la proporción de datos perdidos y cómo se manejaron, la notificación selectiva de los resultados y, por último, si existían sesgos por problemas no abordados anteriormente.

Los desacuerdos entre los dos investigadores fueron resueltos en consenso con el tercer evaluador. Para determinar la concordancia se utilizó el coeficiente kappa de Cohen.

\section{Medidas de resumen y plan de análisis}

Para cada estudio se generó una tabla, en la cual se resumió la información más relevante, la cual incluía si el estudio estaba en forma de resumen o en texto completo, la edad y el sexo de los pacientes, cuál fue la intervención y con qué se comparó, y cuáles fueron los resultados de los estudios (tabla 1).

\begin{tabular}{|c|c|c|c|c|}
\hline Estudio & Edad & Sexo (\% del femenino) & $\begin{array}{l}\text { Intervención- } \\
\text { comparación }\end{array}$ & Resultado \\
\hline $\begin{array}{l}\text { Acyclovir is not effective in } \\
\text { pityriasis rosea: Results of a } \\
\text { randomized, triple-blind, } \\
\text { placebo-controlled trial }^{(11)}\end{array}$ & $\begin{array}{l}\text { - Placebo: }(18,3 \pm 2,66) \text { años. } \\
\text {-Aciclovir: }(24,43 \pm 7,3) \text { años }\end{array}$ & $\begin{array}{l}\text { Placebo: } 23,1 \% \\
\text { Aciclovir,: } 35,7 \% \text { (total } \\
29,6 \% \text { ) }\end{array}$ & $\begin{array}{l}\text { Aciclovir, } 800 \mathrm{mg}, 5 \text { veces al } \\
\text { día por una semana; placebo } \\
\text { idéntico }\end{array}$ & $\begin{array}{l}\text { Días a curación en placebo: } \\
26,54 \pm 9,14 \text {, y con aciclovir: } \\
33,29 \pm 9,49(p=0,072)\left(I C_{95 \%}-\right. \\
0,65-14,14)\end{array}$ \\
\hline $\begin{array}{l}\text { Low dose of acyclovir may be an } \\
\text { effective treatment against } \\
\text { pityriasis rosea: A random } \\
\text { investigator-blind clinical trial } \\
\text { on } 64 \text { patients }{ }^{(13)}\end{array}$ & Mediana de edad: 27,12 años & $\begin{array}{l}\text { No hay información } \\
\text { disponible. }\end{array}$ & $\begin{array}{l}\text { Aciclovir, } 400 \mathrm{mg}, 5 \text { veces al } \\
\text { día, por una semana contra } \\
\text { placebo }\end{array}$ & $\begin{array}{l}\text { Porcentaje de pacientes que } \\
\text { presentaron reducción de las } \\
\text { lesiones a las cuatro semanas: } \\
\text { aciclovir, } 100 \% \text {, y placebo, } \\
80,1 \%\end{array}$ \\
\hline $\begin{array}{l}\text { A randomized, double-blind, } \\
\text { placebo-controlled study of } \\
\text { efficacy of oral acyclovir in the } \\
\text { treatment of pityriasis rosea }\end{array}$ & $\begin{array}{l}\text { No hay información } \\
\text { disponible. }\end{array}$ & $\begin{array}{l}\text { No hay información } \\
\text { disponible. }\end{array}$ & $\begin{array}{l}\text { Aciclovir oral, } 800 \mathrm{mg}, 5 \\
\text { veces al día en adultos y } 20 \\
\mathrm{mg} / \mathrm{kg} / \text { dosis, } 4 \text { veces al día } \\
\text { en niños por } 7 \text { días/placebo }\end{array}$ & $\begin{array}{l}\text { Resolución de las lesiones a los } \\
14 \text { días en pacientes con } \\
\text { aciclovir, } 86,66 \% \text { y con } \\
\text { placebo, } 33,33 \%(p=0,001)\end{array}$ \\
\hline $\begin{array}{l}\text { The comparison between the } \\
\text { efficacy of high dose acyclovir } \\
\text { and erythromycin on the period } \\
\text { and signs of PR }\end{array}$ & $\begin{array}{l}\text {-Acilovir: Mayores de } 35 \\
\text { años: } 46,6 \% \text {, } \\
\text {-Eritromicina: Mayores de } 35 \\
\text { años: } 33,33 \%\end{array}$ & $\begin{array}{l}\text { Aciclovir, 46,66\%, } \\
\text { eritromicina, 53,33\% }\end{array}$ & $\begin{array}{l}\text { Aciclovir, } 4 \mathrm{~g} \text { al día, dividido } \\
\text { en } 5 \text { dosis por } 10 \\
\text { días/eritromicina oral, } 400 \\
\text { mg, } 4 \text { veces al día }\end{array}$ & $\begin{array}{l}\text { Mejoría a las } 8 \text { semanas. } \\
\text { Aciclovir: mejoría completa, } \\
86,66 \% \text {, y parcial, } 13,33 \% \text {. } \\
\text { Eritromicina: mejoría completa, } \\
40 \% \text {, y parcial, } 60 \%(p<0.05)\end{array}$ \\
\hline $\begin{array}{l}\text { Use of high-dose acyclovir in } \\
\text { pityriasis rosea }\end{array}$ & $\begin{array}{l}\text {-Acivlovir: mediana de edad } \\
28,3 \text { años (18-40 años). } \\
\text {-Placebo: mediana de edad } \\
\text { 26,5 (18-37 años) }\end{array}$ & $\begin{array}{l}\text { Aciclovir, } 42,85 \% \text {, placebo, } \\
44,44 \%\end{array}$ & $\begin{array}{l}\text { Aciclovir, } 800 \mathrm{mg}, 5 \text { veces al } \\
\text { día por una semana/placebo } \\
\text { (vitamina C) }\end{array}$ & $\begin{array}{l}\text { Resolución de lesiones en el día } \\
\text { 14: aciclovir: resolución } \\
\text { completa, } 78,6 \% \text {, y parcial, } \\
\text { 11,9\%. Placebo: resolución } \\
\text { completa, } 4,4 \% \text {, y parcial, } 40 \\
\% \text {. }\end{array}$ \\
\hline $\begin{array}{l}\text { Comparative study of } \\
\text { effectiveness of oral acyclovir } \\
\text { with oral erythromycin in the } \\
\text { treatment of Pityriasis rosea }{ }^{(15)}\end{array}$ & $\begin{array}{l}\text {-Aciclovir: } 11 \text { pacientes } \\
\text { menores de } 25 \text { años. } \\
\text {-Eritromicina: } 13 \text { pacientes } \\
\text { menores de } 25 \text { años }\end{array}$ & $\begin{array}{l}\text { Aciclovir, } 38,88 \% \\
\text { Eritromicina } 37,5 \% \text { (total } \\
38,09 \% \text { ) }\end{array}$ & $\begin{array}{l}\text { Aciclovir en adultos, } 800 \mathrm{mg} \text {, } \\
5 \text { veces al día, y en niños, } 20 \\
\mathrm{mg} / \mathrm{kg} / \text { día en } 5 \\
\text { dosis/eritromicina: adultos, } \\
500 \mathrm{mg} \text {, y niños, } 40 \\
\mathrm{mg} / \mathrm{kg} / \text { día en } 4 \text { dosis }\end{array}$ & $\begin{array}{l}\text { Mejoría a las } 6 \text { semanas. } \\
\text { Aciclovir: completa, } 100 \%, \text { y } \\
\text { parcial, } 0 \% \text {. Eritromicina: } \\
\text { completa, } 75 \% \text {, y parcial, } 25 \% \\
(p=0,022)\end{array}$ \\
\hline
\end{tabular}




\begin{tabular}{|c|c|c|c|c|}
\hline Estudio & Edad & Sexo (\% del femenino) & $\begin{array}{l}\text { Intervención- } \\
\text { comparación }\end{array}$ & Resultado \\
\hline $\begin{array}{l}\text { Efficacy of clarithromycin in } \\
\text { pityriasis rosea }\end{array}$ & $\begin{array}{l}\text {-Placebo: } 21,67 \pm 7,42 \text { años } \\
\text {-Claritromicina: } 23.13 \pm 10,34 \\
\text { años }\end{array}$ & $\begin{array}{l}\text { Placebo, } 43,3 \% \\
\text { Claritromicina, } 46,7 \% \text { (total } \\
45 \% \text { ) }\end{array}$ & $\begin{array}{l}\text { Claritromicina, } 500 \mathrm{mg} \text {, dos } \\
\text { veces al día, por una semana } \\
\text { en adultos, y en niños, } 250 \\
\mathrm{mg} \text {, dos veces al día/placebo } \\
\text { (glucosa) }\end{array}$ & $\begin{array}{l}\text { Respuesta terapéutica a las } 6 \\
\text { semanas. Placebo: completa, } \\
80 \% \text {, parcial, } 16,7 \% \text {, y nula, } \\
3,3 \% \text {. Intervención completa, } \\
96,7 \%, \text { parcial, } 3,3 \% \text {, y nula, o } \\
\%(p=0,126)\end{array}$ \\
\hline $\begin{array}{l}\text { The efficacy of azithromycin in } \\
\text { pityriasis rosea: A randomized, } \\
\text { double-blind, placebo- } \\
\text { controlled trial }^{(19)}\end{array}$ & $\begin{array}{l}\text {-Placebo: } 23,66 \pm 8,349 \text { años } \\
\text {-Azitromicina } 23,00 \pm 8,964 \\
\text { años }\end{array}$ & $\begin{array}{l}\text { Placebo, } 51,4 \% \\
\text { Azitromicina, } 45,7 \% \text { (total } \\
48,5 \% \text { ) }\end{array}$ & $\begin{array}{l}\text { Azitromicina, } 12 \mathrm{mg} / \mathrm{kg} / \mathrm{dí} a \\
\text { por } 5 \text { días/placebo }\end{array}$ & $\begin{array}{l}\text { Media de duración de la } \\
\text { enfermedad en días. } \\
\text { intervención: } 12,09 \pm 5,554 \text {, y } \\
\text { placebo, } 11,31 \pm 4,129\end{array}$ \\
\hline $\begin{array}{l}\text { Azithromycin does not cure } \\
\text { pityriasis rosea }^{(20)}\end{array}$ & $\begin{array}{l}\text {-Azitromicina: } 64 \% \text { edades } \\
\text { entee } 5 \text { y } 10 \\
\text {-Placebo: } 54 \% \text { edades entre } 5 \\
\text { y } 10\end{array}$ & $\begin{array}{l}\text { Azitromicina, } 76 \% \\
\text { Placebo, } 58 \%\end{array}$ & $\begin{array}{l}\text { Azitromicina, } 12 \mathrm{mg} / \mathrm{kg} \text { por } \\
\text { dia, máximo } 500 \mathrm{mg} \text { por } 5 \\
\text { dias/placebo }\end{array}$ & $\begin{array}{l}\text { Resolución de lesiones a las } \\
\text { dos semanas. Azitromicina: } \\
\text { resolución completa, } 60 \% \text {, } \\
\text { parcial, } 28 \% \text {, y sin mejoría, } 12 \\
\% \text {. Placebo: resolucion } \\
\text { completa, } 42 \% \text {, parcial, } 29 \% \text {, y } \\
\text { sin mejoría, } 29 \%(p=0,275)\end{array}$ \\
\hline $\begin{array}{l}\text { Erythromycin in pityriasis } \\
\text { rosea: A double-blind, placebo- } \\
\text { controlled clinical trial }^{(17)}\end{array}$ & $\begin{array}{l}\text { No hay información } \\
\text { disponible. }\end{array}$ & $\begin{array}{l}\text { No hay información } \\
\text { disponible. }\end{array}$ & $\begin{array}{l}\text { Eritromicina en dosis dividida } \\
\text { por } 14 \text { días/placebo }\end{array}$ & $\begin{array}{l}\text { Mejoría completa en el grupo } \\
\text { de tratamiento, } 73,3 \%, y \\
\text { ninguna mejoría en el grupo } \\
\text { placebo }(p=0,001)\end{array}$ \\
\hline $\begin{array}{l}\text { UVB phototherapy for pityriasis } \\
\text { rosea: A bilateral comparison } \\
\text { study }{ }^{(21)}\end{array}$ & $\begin{array}{l}\text { No hay información } \\
\text { disponible. }\end{array}$ & $70,50 \%$ & $\begin{array}{l}\text { UVB } 5 \text { veces a la semana por } \\
\text { dos semanas/placebo (UVA) }\end{array}$ & $\begin{array}{l}\text { En } 15 \text { de } 17 \text { pacientes del grupo } \\
\text { de intervención, hubo una } \\
\text { mejoría ( } p=0,0007) \text {. Pero al } \\
\text { hacer el seguimiento, no se } \\
\text { encontró diferencia en el } \\
\text { prurito, el índice de gravedad ni } \\
\text { el tiempo de duración. }\end{array}$ \\
\hline $\begin{array}{l}\text { Treatment of pityriasis rosea } \\
\text { with UV radiation }^{(22)}\end{array}$ & $\begin{array}{l}\text { No hay información } \\
\text { disponible. }\end{array}$ & $60 \%$ & $\begin{array}{l}\text { UV-B } 290-320 \mathrm{~nm} \text { en la mitad } \\
\text { del cuerpo por } 5 \text { días/sin } \\
\text { radiación }\end{array}$ & $\begin{array}{l}\text { Prurito: } 9 \text { pacientes tuvieron } \\
\text { mejoría significativa del prurito } \\
(p<0,01) \text {. } \\
\text { Extensión de la enfermedad: } 10 \\
\text { pacientes tuvieron mejoría } \\
\text { significativa en el lado del } \\
\text { tratamiento }(p=0,001) \text {. }\end{array}$ \\
\hline \multirow{3}{*}{$\begin{array}{l}\text { Double blind randomized } \\
\text { placebo controlled trial to } \\
\text { evaluate the efficacy and safety } \\
\text { of short-course low-dose oral } \\
\text { prednisolone in pityriasis rosea } \\
\text { (23) }\end{array}$} & $\begin{array}{l}\text {-Prednisolona: } 26,03 \pm 7,83 \\
\text { años }\end{array}$ & Prednisolona, $48 \%$ & \multirow{3}{*}{$\begin{array}{l}\text { Prednisolona, } 20 \text { mg/día, } \\
\text { después del desayuno por } 5 \\
\text { días, } 15 \mathrm{mg} / \text { día por los } \\
\text { siguientes } 5 \text { días y } 10 \mathrm{mg} / \text { día } \\
\text { por los últimos } 5 \\
\text { días/placebo }\end{array}$} & $\begin{array}{l}\text { La media del prurito según la } \\
\text { escala visual análoga para la } \\
\text { semana } 2 \text { en el grupo de } \\
\text { tratamiento, fue de } \pm 1,02 \text { y, } \\
\text { para el grupo con placebo, } \\
\pm 1,10 \text { (p<o,001). }\end{array}$ \\
\hline & 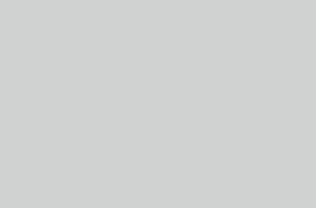 & 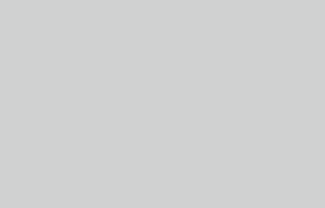 & & $\begin{array}{l}\text { La media de la escala de } \\
\text { gravedad para la semana } 2 \text { en } \\
\text { el grupo con tratamiento fue de } \\
\pm 5,32 \text { y, en el grupo control, de } \\
\pm 5,20 \text { (p<o, 001). }\end{array}$ \\
\hline & -Placebo: $25,86 \pm 7,78$ años & Placebo, $54 \%$ & & $\begin{array}{l}\text { Después de } 12 \text { semanas de } \\
\text { seguimiento, los pacientes del } \\
\text { grupo con tratamiento con } \\
\text { prednisolona tuvieron un mayor } \\
\text { número de recaídas que los del } \\
\text { grupo con placebo. }\end{array}$ \\
\hline
\end{tabular}

Tabla 1. Datos relevantes de los ensayos clínicos incluidos 


\section{RESULTADOS}

\section{Selección de estudios}

Se encontraron 88 reportes de pitiriasis rosada filtrados como ensayos clínicos durante la búsqueda inicial en las bases de datos bibliográficas Pubmed, Embase, Lilacs y Central. En la búsqueda, el coeficiente kappa de Cohen fue de 0,78 ( IC $_{95 \%}$ o,68-0,89) (figuras 1 y 2).

\section{Participantes}

Los estudios incluidos aportaron en total 667 pacientes con diagnóstico de pitiriasis rosada.

\section{Intervención}

En los estudios se evaluaron intervenciones diferentes, terapia antiviral (aciclovir), tratamiento antibiótico (claritromicina, eritromicina, azitromicina), tratamiento con corticoesteroides (prednisolona) y fototerapia (luz UVB).

\section{Control}

El control no fue el mismo para todos los estudios. En 10 estudios $(76,9 \%)$ el control se hizo con placebo, en algunos casos idéntico y en otros no. En los otros estudios, el control fue con tratamiento antibiótico (eritromicina) o sin ningún tratamiento.

\section{Riesgo de sesgos de los estudios incluidos}

Los detalles de la calidad metodológica de los estudios individuales se presentan en la figura 2. Del total de artículos incluidos, hubo ocultación de la asignación en 4 de los estudios. El acuerdo evaluado por el coeficiente kappa fue de 0,87 ( IC $_{95 \%}$ o,80-0,94).

Dada la heterogeneidad en los tipos de intervenciones evaluadas, los grupos de comparación y los resultados medidos en los estudios, no se realizó un metaanálisis.

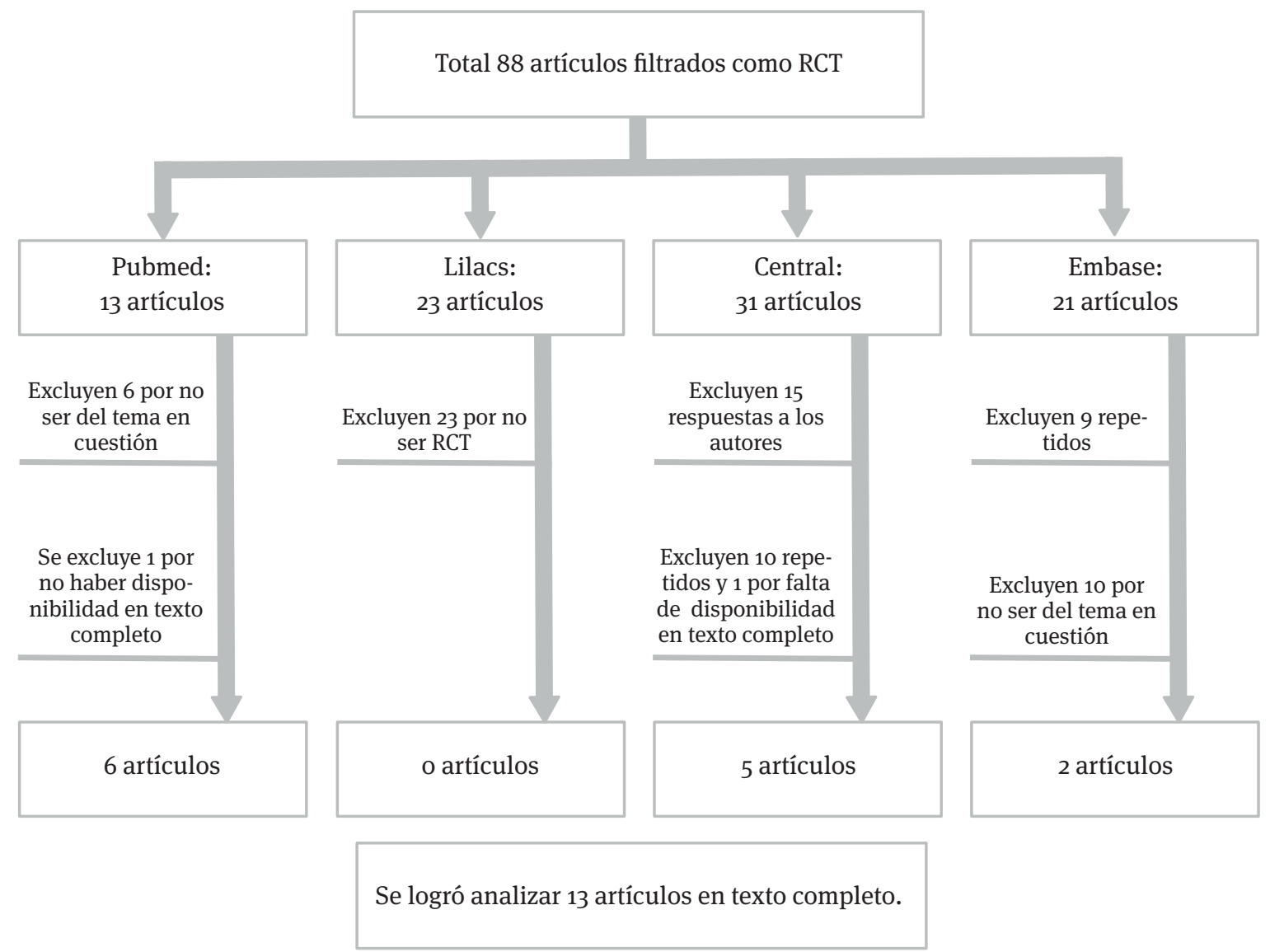

Figura 1. Flujograma de la búsqueda en las diferentes bases de datos, artículos excluidos e incluidos. 


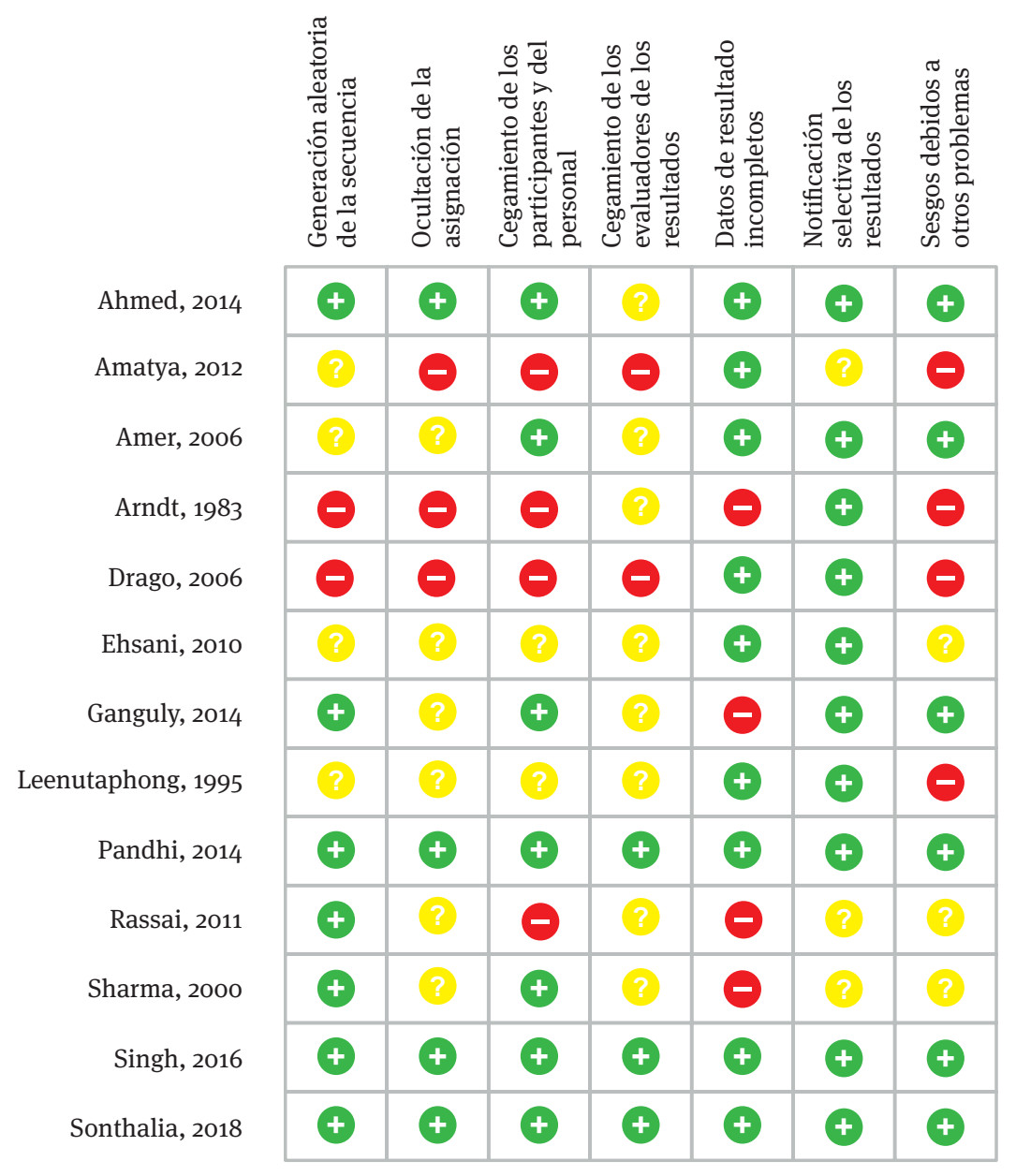

Figura 2. Resumen del riesgo de sesgo en los estudios individuales agrupados en siete dominios que evaluaron las diferentes fuentes potenciales de sesgo. La calificación se realizó por color: verde indica un bajo riesgo de sesgo, amarillo indica un riesgo desconocido, y el rojo indica un alto riesgo de sesgo.

\section{DISCUSIÓN}

La expresión 'pitiriasis rosada' fue utilizada por primera vez por Gilbert en 1860 y significa 'escamas rosadas'. Se trata de una erupción cutánea común, aguda y de resolución espontánea que, típicamente, comienza como una placa ovalada única y escamosa en el tronco, conocida como el 'parche heráldico', la cual, en el transcurso de días a semanas, se acompaña de múltiples lesiones similares más pequeñas localizadas a lo largo del tronco en un patrón de árbol de na$\operatorname{vidad}^{(8)}$. La pitiriasis rosada es una dermatosis relativamente común de etiología indeterminada, que se cree que tiene un origen asociado al virus herpes 6 y $7^{(9)}$. $\mathrm{Al}$ ser de resolución espontánea, la pitiriasis rosada se trata generalmente de manera sintomática, con antihistamínicos y emolientes y en algunas ocasiones se ha recomendado iniciar tratamientos adicionales, especialmente, si el compromiso es mayor y teniendo en cuenta las características del paciente, como su edad o si está en embarazo ${ }^{(10)}$.

Entre los ensayos clínicos incluidos, se evaluó la efectividad del aciclovir en el tratamiento de la pitiriasis rosada. Esta intervención se comparó con placebo o con eritromicina. Se incluyeron 6 estudios, 4 con placebo y 2 con eritromicina.

En el primer estudio, de Singh, et al., se comparó el uso durante una semana de aciclovir, $800 \mathrm{mg}, 5$ veces al día, y un placebo; se concluyó que el aciclovir no era efectivo en el tratamiento de la pitirasis rosada. Los autores discuten que este resultado puede deberse a la ausencia de síntomas sistémicos en sus pacientes, lo cual implicaría que no hubo reactivación del virus y que el papel etiológico de los virus herpes 6 y 7 no fue 
significativo para estos pacientes ${ }^{(11)}$.

En otro estudio se buscaba comparar el aciclovir con un placebo, y se encontró que el grupo que recibió tratamiento presentó mayor resolución a los días 7 y 14, en comparación con los pacientes que recibieron placebo $^{(12)}$, resultado similar a los del estudio que comparaba dosis bajas de aciclovir con un placebo, en el cual se encontró que era efectivo para disminuir la duración de la pitiriasis y podía utilizarse, sobre todo en pacientes con prurito intenso o compromiso extenso ${ }^{(13)}$. En otro estudio en que se comparó el uso de aciclovir a altas dosis (80o mg, 5 veces al día), se encontró que su uso disminuía el tiempo hasta la resolución, sobre todo en aquellos pacientes en quienes el tratamiento se iniciaba en la primera semana desde la aparición de las lesiones ${ }^{(14)}$.

En cuanto a los ensayos clínicos que comparaban la eficiencia del uso de aciclovir con la de la eritromicina en la resolución de la pitiriasis rosada, se encontró que, aunque ambos tratamientos eran efectivos en disminuir la gravedad y la duración de la reacción exantemática, el aciclovir era mejor que la eritromicina ${ }^{(15)}$; en el otro estudio en que se comparó el aciclovir con la eritromicina, se obtuvieron resultados similares; el uso de aciclovir estaba asociado con la resolución completa de la reacción cutánea y resolución más rápida del prurito, en comparación con la eritromicina ${ }^{(16)}$.

En lo referente al uso de antibióticos, no se sabe con exactitud el mecanismo de acción por el cual actúan en la pitirasis rosada, aunque se sabe que los macrólidos tienen actividad inmunomoduladora y antiinflamatoria, por lo que su efectividad no implicaría una etiología bacteriana ${ }^{(2)}$. Se incluyeron 6 estudios, en los cuales se comparó cada antibiótico (eritromicina, claritromicina o azitromicina).

En el primer estudio en el que se utilizó eritromicina, se encontró una diferencia estadísticamente significativa entre el grupo de intervención y el grupo control, que fue placebo, para el resultado estudiado que era la resolución completa ${ }^{(17)}$; en los demás estudios incluidos en los cuales se comparó eritromicina con aciclovir, esta no tuvo mejores resultados que el aciclovir, sin embargo, se obtuvo respuesta estadísticamente significativa al tratamiento en ambos estudios ${ }^{(15)(16)}$.

Para el tratamiento con claritromicina, en el único estudio que fue incluido, aunque no se reportaron los análisis estadísticos respectivos, se encontró que la mayoría, 45 de 48 pacientes del grupo intervención presentaron resolución de la reacción exantemática en la primera semana ${ }^{(18)}$.

En dos estudios se comparó la azitromicina bajo la misma dosis con un placebo. En el primer estudio, se encontró que el uso de la azitromicina no modificaba el curso de la enfermedad ni disminuía el prurito reportado por el paciente ${ }^{(19)}$, resultado similar al del segundo estudio, en el cual se hallaron resultados semejantes entre el grupo de intervención y el control en cuanto a la resolución y la aparición de nuevas lesiones de pacientes con pitiriasis rosada ${ }^{(20)}$.

La fototerapia con radiación ultravioleta es otra intervención analizada en dos estudios incluidos. En el primer estudio, se encontró inicialmente una diferencia estadísticamente significativa entre el grupo de intervención y el de placebo, pero al hacer el seguimiento, no hubo diferencia para el índice de gravedad, prurito o duración de la reacción exantemática ${ }^{(21)}$. En el segundo estudio, hubo diferencias estadísticamente significativas en cuanto a la extensión de la enfermedad y el prurito, en comparación con el grupo control (22).

Por último, en un estudio se comparó el uso de corticoesteroides orales y un placebo, y se concluyó que no se recomendaba el uso rutinario de esteroides en pacientes con pitiriasis rosada; su uso se justificaría en pacientes muy comprometidos y muy sintomáticos ${ }^{(23)}$.

\section{CONCLUSIÓN}

La revisión bibliográfica de las intervenciones terapéuticas para la pitiriasis rosada arroja 'evidencia' diversa de los diferentes tratamientos.

Se puede concluir que el aciclovir fue efectivo en 4 de 6 estudios, en los cuales se logró disminuir el tiempo hasta la resolución de la reacción exantemática y el prurito, pero no se pudo hacer un metaanálisis por la gran heterogeneidad en las dosis, el grupo de comparación, el tiempo de seguimiento y el tipo de resultado. En cuanto a la terapia antibiótica con macrólidos, no se recomendaría la azitromicina al encontrar que su uso no modifica el curso de la enfermedad; sin embargo, para la eritromicina y la claritromicina, es necesario hacer más estudios, pues a pesar de que hubo resultados a favor de dichos antibióticos en cuanto al tiempo de resolución de la enfermedad, no se encontró superioridad cuando se compara con otras intervenciones como aciclovir y se encontraron pocos estudios comparando estos antibióticos.

Los estudios en que se comparó la fototerapia, además de ser antiguos, el diseño metodológico no era bueno, pero arrojaron resultados positivos en cuanto al tiempo de resolución y disminución del prurito.

Por último, no se recomienda rutinariamente el tratamiento con esteroides, sino limitarlo a casos con sintomatología grave o compromiso extenso. 


\section{REFERENCIAS}

1. Wolff K. Fitzpatrick Dermatología en Medicina General. Buenos Aires: Editorial Médica Panamericana; 2009. p. 65-7.

2. Chuh AA, Dofitas BL, Comisel G, Reveiz L, Sharma $\mathrm{V}$, Garner SE, et al. Interventions for pityriasis rosea. Cochrane Database Syst Rev. 2007. Fecha de consulta: 16 de abril de 2018. Disponible en: http://doi.wiley.com/10.1002/14651858.CDoo5068. pub2.

3. Nair PA, Bhimji SS. Pityriasis rosea. Stat Pearls. 2018. Fecha de consulta: 27 de junio de 2018. Disponible en: https://www.ncbi.nlm.nih.gov/ books/NBK448091/

4. Drago F, Vecchio F, Rebora A. Use of high-dose acyclovir in pityriasis rosea. J Am Acad Dermatol. 2006;54:82-5.

5. Goldstein A, Goldstein BG, Delavalle R. Pityriasis rosea - UpToDate. Fecha de consulta: 16 de abril de 2018. Disponible en: https://www.uptodate.com/ contents/pityriasis-rosea.

6. Higgins JP, Green S. Cochrane handbook for systematic reviews of interventions. The Cochrane Collab. 2011. Fecha de consulta: 27 de junio de 2018. Disponible en: https://es.cochrane.org/sites/ es.cochrane.org/files/public/uploads/Manual_Cochrane_510_reduit.pdf.

7. Moher D, Liberati A, Tetzlaff J, Altman DG. Academia and clinic preferred reporting items for systematic reviews and meta-analyses. Ann Intern Med. 2009;151:264-9.

8. Goldsmith LA, Katz SI, Gilchrest BA, Paller AS, Leffell DJ, editors. Fitzpatrick's Dermatology in General Medicine. 8 th edition. New York: McGrawHill Medical; 2012 Cap 42. Fecha de consulta: 27 de junio de 2018. Disponible en: https://accessmedicine.mhmedical.com/book.aspx?bookID=392

9. Urbina F, Das A, Sudy E. Clinical variants of pityriasis rosea. World J Clin Cases. 2017;5:203.

10. Chuh A, Zawar V, Sciallis G, Kempf W. A position statement on the management of patients with pityriasis rosea. J Eur Acad Dermatology Venereol. 2016;30:1670-81.

11. Singh S, Anurag, Tiwary N. Acyclovir is not effective in pityriasis rosea: Results of a randomized, triple-blind, placebo-controlled trial. Indian J Dermatology Venereol Leprol. 2016;82:505.

12. Ganguly S. A randomized, double-blind, placebocontrolled study of efficacy of oral acyclovir in the treatment of Pityriasis rosea. J Clin Diagnostic Res. 2014;8:1-4.
13. Rassai S, Feily A, Sina N, Abtahian S. Low dose of acyclovir may be an effective treatment against pityriasis rosea: A random investigator-blind clinical trial on 64 patients. J Eur Acad Dermatology Venereol. 2011;25:24-6.

14. Drago F, Vecchio F, Rebora A. Use of high-dose acyclovir in pityriasis rosea. J Am Acad Dermatol. 2006;54:82-5.

15. Amatya A, Rajouria EA, Karn DK. Comparative study of effectiveness of oral Acyclovir with oral erythromycin in the treatment of pityriasis rosea. Kathmandu Univ Med J. 2012;10:57-61.

16. Noormohammadpour P, Toosi S, Hosseinpour A, Hosseini M, Sayanjali S, Ehsani A, et al. The comparison between the efficacy of high dose acyclovir and erythromycin on the period and signs of pitiriasis rosea. Indian J Dermatol. 2010;55:246.

17. Sharma P, Yadav T, Gautam R, Taneja N, Satyanarayana L. Erythromycin in pityriasis rosea: A double-blind, placebo-controlled clinical trial. J Am Acad Dermatol. 2000;42:241-4.

18. Ahmed N, Iftikhar N, Bashir U, Rizvi SDA, Sheikh ZI, Manzur A. Efficacy of clarithromycin in pityriasis rosea. J Coll Physicians Surg Pak. 2014;24:802-5.

19. Pandhi D, Singal A, Verma P, Sharma R. The efficacy of azithromycin in pityriasis rosea: A randomized, double-blind, placebo-controlled trial. Indian J Dermatol Venereol Leprol. 2014;80:36.

20. Amer A. Azithromycin does not cure pityriasis rosea. Pediatrics. 2006;117:1702-5.

21. Leenutaphong V, Jiamton S. UVB phototherapy for pityriasis rosea: A bilateral comparison study. J Am Acad Dermatol. 1995;33:996-9.

22. Arndt KA, Paul BS, Stern RS, Parrish JA. Treatment of pityriasis rosea with UV radiation. Arch Dermatol. 1983;119:381-2.

23. Sonthalia S, Kumar A, Zawar V, Priya A, Yadav P, Srivastava S, et al. Double-blind randomized placebo-controlled trial to evaluate the efficacy and safety of short-course low-dose oral prednisolone in pityriasis rosea. J Dermatolog Treat. 2018; 617622. 